\title{
Ochratoxin A induces apoptosis in neuronal cells
}

\author{
Xiangnan Zhang • Christine Boesch-Saadatmandi • \\ Yijia Lou - Siegfried Wolffram · Patricia Huebbe • \\ Gerald Rimbach
}

Received: 24 October 2008/Accepted: 11 December 2008/Published online: 16 January 2009

(C) Springer-Verlag 2009

\begin{abstract}
The mycotoxin ochratoxin A (OTA), which is produced by Aspergillus and Penicillium subspecies, is a frequently present contaminant of food and feedstuffs. OTA exhibits a wide range of toxic activities including nephro- and hepatotoxicity. However, little is known regarding potential neurotoxic effects of OTA. In the present study primary neurons as well as SH-SY5Y neuronal cells were incubated with increasing concentrations of OTA $(0.1-2.5 \mu \mathrm{mol} / \mathrm{L})$. OTA treatment resulted in a dose-dependent increase in cytotoxicity in both neuronal cell types. Caspase- 9 and caspase- 3 were activated in response to OTA treatment. Furthermore, caspase inhibitors were effective in partly counteracting OTA induced neurocytotoxicity. OTA induced apoptosis was accompanied by a loss of mitochondria membrane potential. Overall, present data indicated that OTA is neurotoxic at relatively low concentrations. OTA induced neurotoxicity seems to be, at least party, mediated by apoptosis. OTA may contribute to the pathogenesis of neurodegenerative diseases (e.g. Alzheimer's and Parkinson's disease) in which apoptotic processes are centrally involved.
\end{abstract}

\footnotetext{
X. Zhang · Y. Lou

Institute of Pharmacology, Toxicology and Biochemical Pharmaceutics, College of Pharmaceutical Sciences,

Zhejiang University, 310058 Hangzhou, China

C. Boesch-Saadatmandi · P. Huebbe · G. Rimbach ( $₫)$ Institute of Human Nutrition and Food Science, Christian Albrechts University Kiel,

Hermann-Rodewald-Strasse 6, 24098 Kiel, Germany

e-mail: rimbach@foodsci.uni-kiel.de
}

\section{S. Wolffram}

Institute of Animal Nutrition and Physiology,

Christian Albrechts University, Kiel, Germany
Keywords Ochratoxin A · Mycotoxin - Neurons · Apoptosis · Programmed cell death · Neurotoxicity · Alzheimer's disease

\section{Introduction}

The mycotoxin ochratoxin A (chemical structure is given in Fig. 1) is a fungal metabolite produced by several subspecies of the genera Penicillium and Aspergillus. Their widespread occurrence and the persistence of OTA in the food chain may contribute to a significant OTA exposure to humans $[25,26]$. In fact OTA has been frequently found in the human blood [20]. The kidney is the main target tissue of OTA toxicity $[10,19]$. In addition to its nephrotoxic effects, hepato-, terato- and immunotoxic activities of OTA have also been reported $[18,24]$. OTA has been classified as a putative human carcinogen by the International Agency for Research on Cancer (IARC [14]).

Furthermore, recent findings indicate that OTA may, to some extent, also affect the neuronal system [2, 27]. Studies in rodents suggest that OTA crosses the blood brain barrier and accumulates in most parts of the brain as a function of time and concentration [2, 27, 28]. After administration of a single OTA dose to mice $(3.5 \mathrm{mg} / \mathrm{kg}$ body weight; i.p.), highest OTA concentrations were measured in the cerebellum $(1.7 \mathrm{ng} / \mathrm{mg})$ and the pons $(0.7 \mathrm{ng} / \mathrm{mg})$ followed by the cerebral cortex $(0.3 \mathrm{ng} / \mathrm{mg})$ [28]. Interestingly, the sites of OTA accumulation and tissue susceptibility towards OTA induced toxicity in the brain did not always correlate. However, the hippocampus, a primary site of neurodegeneration in Alzheimer's disease, turned out to exhibit relatively high OTA levels with concurrently pronounced OTA neurotoxicity [3]. In this context, Sava and coworkers [28] hypothesized that low 
<smiles>C[C@H]1Cc2c(Cl)cc(C(=O)NC(Cc3ccccc3)C(=O)O)c(O)c2C(=O)O1</smiles>

Fig. 1 Chemical structure of ochratoxin A

level exposure of OTA may exert delayed neurotoxic effects which may in turn contribute to the development of neurodegenerative disorders. Interestingly, OTA has also been shown to cause widespread oxidative stress as measured by an increase in lipid peroxidation and DNA damages in mice brain [27], features that are associated with a number of neurodegenerative disorders including Parkinson's and Alzheimer's disease. However, the underlying molecular mechanisms for OTA neurotoxicity are not fully understood. The present study in cultured neurons aimed at investigating whether OTA induced neurotoxicity may be mediated by apoptosis.

\section{Materials and methods}

Cell culture

SH-SY5Y neuroblastoma cells were routinely cultured in RPMI 1640 medium supplemented with 5\% fetal bovine serum, $5 \mathrm{mmol} / \mathrm{L}$ glutamine, $1 \mathrm{mmol} / \mathrm{L}$ MEM sodium pyruvate, 1\% MEM non-essential amino acids, 1\% MEM vitamins, with $100 \mathrm{IU} / \mathrm{mL}$ penicillin and $100 \mu \mathrm{g} / \mathrm{mL}$ streptomycin (all from PAA, Pasching, Austria) under standard conditions $\left(37^{\circ} \mathrm{C}\right.$, humidified $5 \% \quad \mathrm{CO}_{2}$ atmosphere). Cells were subcultured every 4-5 days after reaching $80 \%$ confluence and seeded at an initial density of $6.3 \times 10^{4}$ cells $/ \mathrm{cm}^{2}$ in 24-well and 6-well plates for further experiments.

Primary rat cortical neuronal cell culture was carried out as previously described with minor modifications [9, 32]. Briefly, neonatal Wistar rats were sacrificed; cortices were separated on ice and cut into pieces prior digestion in $0.25 \%$ trypsin for $15 \mathrm{~min}$ at $37^{\circ} \mathrm{C}$. Cortical tissue lysate was then passaged through a series of fire-polished pipettes to get a single cell suspension. After centrifuging, cells were resuspended in Neurobasal medium supplemented with 2\% B27 (Invitrogen, Carlsbad, CA, USA), $100 \mathrm{IU} / \mathrm{mL}$ penicillin, $100 \mu \mathrm{g} / \mathrm{mL}$ streptomycin and seeded at $1 \times 10^{5} \mathrm{cells} / \mathrm{cm}^{2}$ in poly-D-lysine (Sigma, Deisenhofen, Germany) coated plates. Culture medium was refreshed every $2-3$ days and cells were kept under standard conditions 7 days before further treatment.
Ochratoxin A (obtained from Sigma) was dissolved in methanol $(5 \mathrm{mmol} / \mathrm{L}$ stock solution) and further diluted in culture medium before use. Cells were treated with 0.1 , $0.25,0.5,1.0$ and $2.5 \mu \mathrm{mol} / \mathrm{L}$ of OTA in serum or B27 free medium as described above prior to the neutral red assay or cell collection.

Control cells were supplemented with $0.1 \%$ methanol as a vehicle control. In the caspase inhibitor experiments, Z-VAD-fmk and Z-DEVD-fmk (R\&D system Inc., MN, USA) were dissolved in phosphate buffered saline (PBS) at $20 \mathrm{mmol} / \mathrm{L}$ and were further diluted by corresponding serum or B27 free medium to working concentrations. Cells were pre-incubated with Z-VAD-fmk or Z-DEVDfmk for $24 \mathrm{~h}$ followed by a $24 \mathrm{~h}$ exposure with OTA without Z-VAD-fmk or Z-DEVD-fmk. After that, cell viability was determined by the neutral red assay. For DNA laddering, cells were treated with $0.1,0.25,0.5,1.0,2.5$ and $5.0 \mu \mathrm{mol} / \mathrm{L}$ of OTA for $48 \mathrm{~h}$ in serum or B27-free medium before collection.

Neutral red assay

Cell viability was assessed by the neutral red assay as described previously [7]. Briefly, cells, after treatment with OTA, were washed with PBS. New medium supplemented with $50 \mu \mathrm{g} / \mathrm{ml}$ neutral red was added and incubated for $1.5 \mathrm{~h}$. Subsequently, neutral red medium was removed and the incorporated neutral red dye was extracted from the cells using bleaching solution (50\% ethanol, $49 \%$ distilled water and $1 \%$ acetic acid). The absorbance was read at $540 \mathrm{~nm}$ using a plate reader (Labsystems, Helsinki, Finland) and cell viability expressed as percent viability compared to control cells (vehicle treated cells).

\section{DNA laddering}

Following OTA treatment for $48 \mathrm{~h}$, cells were rinsed twice with PBS and collected by centrifuging at $1,500 \times \mathrm{g}$ for $5 \mathrm{~min}$. Cell pellets were lysed in $10 \mathrm{mmol} / \mathrm{L}$ Tris-HCI buffer $(0.1 \mathrm{~mol} / \mathrm{L} \mathrm{NaCI}, 10 \mathrm{mmol} / \mathrm{L}$ EDTA, $0.5 \%$ SDS, $500 \mu \mathrm{g} / \mathrm{mL}$ proteinase $\mathrm{K}, \mathrm{pH} 7.5)$ and incubated at $50^{\circ} \mathrm{C}$ for $3 \mathrm{~h}$. The same volume of chloroform was added and the samples were centrifuged to separate phases. Then, the upper phase was mixed with $50 \mu \mathrm{l}$ of $3 \mathrm{~mol} / \mathrm{L}$ sodium acetate and methanol to precipitate the DNA. DNA was obtained by centrifuging at $12,000 \mathrm{rpm}$ for $30 \mathrm{~min}$ at $4^{\circ} \mathrm{C}$, following a washing step with $75 \%$ ethanol. The DNA pellet was dissolved in RNase containing buffer $(10 \mathrm{mmol} /$ L Tris-HCI, 1 mmol/L EDTA, $200 \mu \mathrm{g} / \mathrm{mL}$ RNnase (RNase cocktail; Ambion, Austin, TX, USA), pH 8.0) and incubated for $30 \mathrm{~min}$ at $37^{\circ} \mathrm{C} .10 \mu \mathrm{g}$ of total DNA was loaded for agarose gel electrophoresis. DNA ladders were visualized under UV light and images were taken using a 
Bio-Rad ChemiDoc system (Bio-Rad Laboratories, Hercules, CA, USA). Lyophilized apoptotic U937 cells in which apoptosis was induced by camptothecine were purchased from Roche Applied Science (Roche Diagnostics GmbH, Mannheim, Germany) and used as positive controls.

\section{Western blotting}

Following OTA treatment, cells were harvested and lysed in RIPA buffer $(50 \mathrm{mmol} / \mathrm{L}$ Tris- $\mathrm{HCl}, 150 \mathrm{mmol} / \mathrm{L} \mathrm{NaCl}$, $0.5 \%$ sodium deoxycholate, $0.1 \%$ SDS, $1 \%$ NP-40, $20 \mathrm{mmol} / \mathrm{L}$ EGTA, $1 \mathrm{mmol} / \mathrm{L}$ DTT, $20 \mathrm{mmol} / \mathrm{L} \mathrm{NaF}$, $1 \mathrm{mmol} / \mathrm{L}$ sodium vandate, proteinase inhibitor cocktail). Cell lysates were purified by centrifugation $\left(4^{\circ} \mathrm{C}\right.$, $14,000 \times \mathrm{g}, 30 \mathrm{~min})$ and the protein concentration determined using BCA Protein Assay Kit (Pierce, IL, USA). $40 \mu \mathrm{g}$ of total protein was separated on a $12 \%$ SDS/polyacrylamide gel followed by protein transfer to a PVDF membrane and blocked in 5\% non-fat milk in Tris-buffered saline (TBS). Primary antibodies were added in TBS with 5\% non-fat milk: anti-caspase 3 and anti-caspase 9 (each 1:500; Cell Signaling Technology, Inc. Danvers, MA, USA), anti-caspase 8 (1:800; Millipore, Schwalbach, Germany), anti- $\beta$-actin (1:1,000; Santa Cruz Biotechnology) and incubated over night at $4{ }^{\circ} \mathrm{C}$. The blots were washed and incubated with the secondary antibody (antimouse horseradish peroxidase; Santa Cruz Biotechnology) in TBS with 5\% non-fat milk $(1: 5,000)$. The blots were exposed to Immun-Star Western Chemiluminescent Kit (Bio-Rad) and scanned using a ChemiDoc system (Bio-Rad). Digital images were captured and quantified using the Quantity One system. Relative concentrations of target proteins were quantified as the ratio between the amount of target protein and the amount of the housekeeping protein $\beta$-actin. We have checked the molecular weight of all proteins detected by Western blotting using molecular weight markers.

Mitochondrial membrane potential assessment by JC-1 staining

To assess the mitochondrial membrane potential $(\Delta \Psi \mathrm{m})$, JC-1 staining was used. JC-1 is a cationic dye that exhibits membrane potential-dependent accumulation in mitochondria, as indicated by a fluorescence emission shift from green $(\lambda 525 \mathrm{~nm})$ to red $(\lambda 610 \mathrm{~nm})$. Mitochondria depolarization is specifically indicated by a decrease in the red to green fluorescence intensity ratio [34]. Following OTA treatment cells were incubated with JC-1 following the manufacture's protocol of the JC-1 staining kit (Sigma). Valinomycin treated cells were taken as positive control. Fluorescent images were taken by fluorescence microscopy (Carl Zeiss MicroImaging GmbH, Hamburg, Germany).
Statistical analysis

Results are expressed as mean with standard deviation (SD) of three to four independent passages performed in duplicate or triplicate. Statistical analysis was carried out with SPSS Version 15.0. Normally distributed data were compared via $t$ test; otherwise, the non-parametric MannWhitney $U$ test was used.

\section{Results}

OTA induced cell death in SH-SY5Y cells and primary neurons

OTA exposure of both SH-SY5Y cells and primary neurons for $24 \mathrm{~h}$ resulted in a significant decrease of cell viability in a concentration-dependent manner. As shown in Fig. 2A, primary neurons and SH-SY5Y did react differently in response to the OTA treatment. In fact, increasing the amount of OTA from 0.5 to $2.5 \mu \mathrm{mol} / \mathrm{L}$ did not decrease the viability of SH-SY5Y but further decreased the viability of primary neurons indicating a higher susceptibility of primary neurons towards the OTA treatment.

Morphological changes of the cells in response to the OTA treatment were observed by light microscopy. As shown in Fig. 2B, after $1.0 \mu \mathrm{mol} / \mathrm{L}$ OTA exposure, fewer SH-SY5Y cells were attached to the culture plate surface and more detached and dead cells could be observed (white arrows). In primary neurons, untreated control cells exhibited large vacuole-free cell bodies with elaborate networks of neurites. Exposure to OTA lead to, besides the decrease in cell density, less neurites and some tubercles (black arrows), which is a typical phenomenon of neuronal injury.

Caspase dependent apoptosis in SH-SY5Y and primary neurons induced by OTA

In order to elaborate on the mechanisms of OTA mediated cytotoxicity, a DNA fragmentation assay was conducted in SH-SY5Y cells after $48 \mathrm{~h}$ of OTA treatment. As shown in Fig. 3A, a concentration-dependent DNA laddering could be found in OTA treated cells, indicating that the majority of cells may undergo apoptosis rather than necrosis. Furthermore, since caspases play an important role in apoptosis, caspase- $8,-9$ and -3 protein levels were determined by Western blotting. Figure 3B indicates that caspase- 9 and caspase- 3 were activated following OTA treatment in both primary neurons and SH-SY5Y cells while caspase- 8 remained largels unchanged in response to OTA treatment (data not shown). In primary neurons the 
Fig. 2 Viability and morphology of SH-SY5Y cells and primary neurons after $24 \mathrm{~h}$ incubation with OTA. A Cells were treated with various concentrations of OTA $(0.1-$ $2.5 \mu \mathrm{mol} / \mathrm{L}$ ) and cell viability was determined by the neutral red assay. Data are expressed as mean with $\mathrm{SD}(n=3)$. $* P<0.05 ; * * P<0.01$ versus control. B Microphotography was performed after OTA incubation. a Vehicle control, b $0.25 \mu \mathrm{mol} / \mathrm{L}$ OTA, and c $1.0 \mu \mathrm{mol} / \mathrm{L}$ OTA in SH-SY5Y cells; d vehicle control, e $0.5 \mu \mathrm{mol} / \mathrm{L}$ OTA and f $1.0 \mu \mathrm{mol} / \mathrm{L}$ OTA in primary neurons. White arrows indicate insulted and detached cells, black arrows indicate tubercles in neuritis $($ Bar $=50 \mu \mathrm{m})$
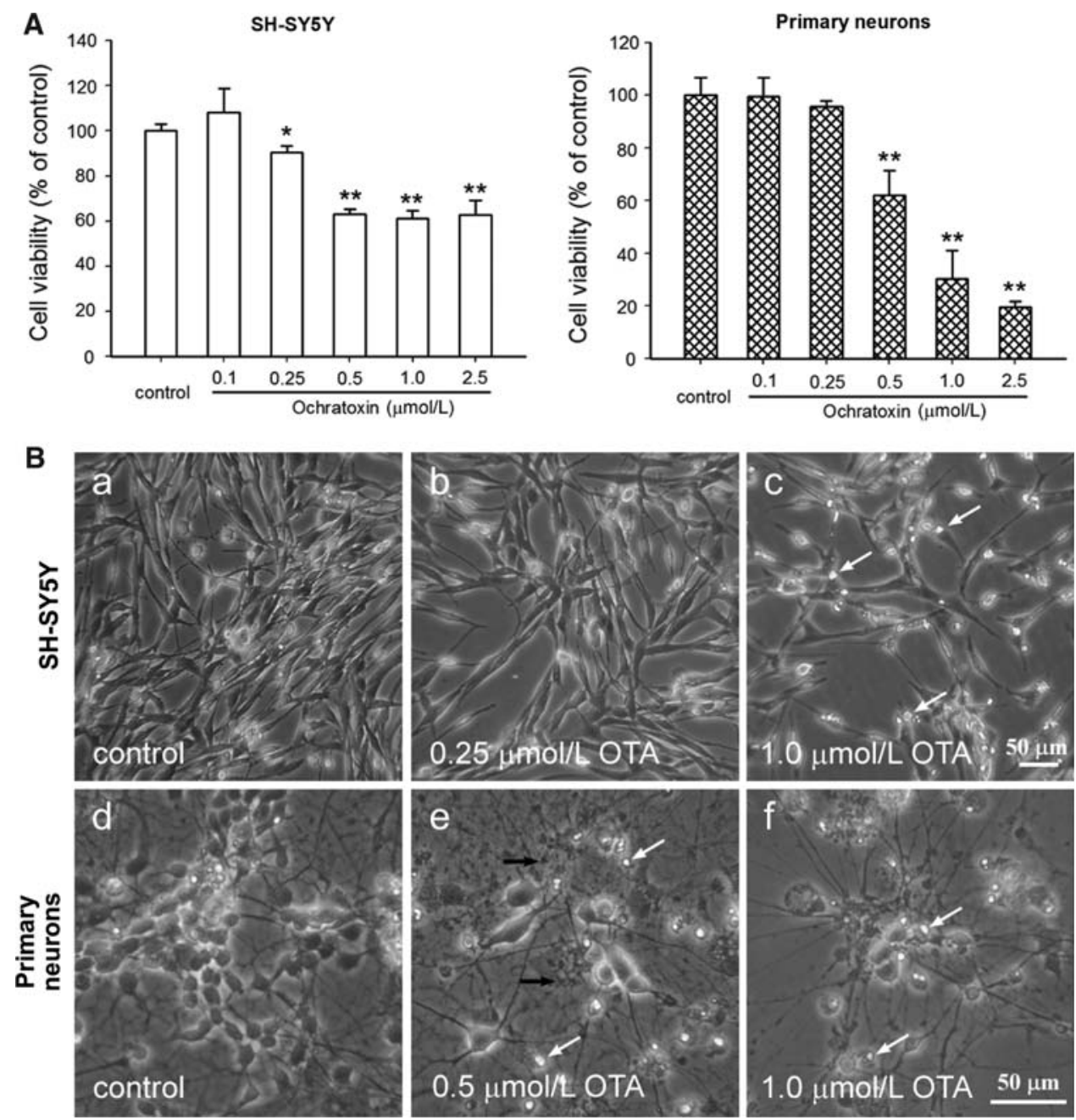

activation of caspase-3 seems to follow a bell-shaped curve peaking at $1 \mu \mathrm{mol} / \mathrm{L}$ OTA. In contrast, caspase-3 activation in SH-SY5Y cells appears to be rather dose-dependent. In order to study whether OTA exposure leads to cell death via a caspase dependent pathway, two caspase inhibitors, Z-VAD-fmk (pan caspases inhibitor) and Z-DEVD-fmk (caspase-3 specific inhibitor) were used in the presence of OTA. As shown in Fig. 3C and D, both Z-VAD-fmk and ZDEVD-fmk were effective in preventing OTA induced cell toxicity. Taken together, present data suggest that OTA leads to a caspase dependent apoptosis in both SH-SY5Y cells and primary neurons.

Effect of OTA on the mitochondria membrane potential $(\Delta \Psi \mathrm{m})$

Since mitochondria are centrally involved in programmed cell death, the effect of OTA on the mitochondria membrane potential was studied. Loss of $\Delta \Psi \mathrm{m}$, which is indicative for mitochondria dysfunction, leads to cytochrome $\mathrm{c}$ release from the inner mitochondria membrane which in turn triggers other apoptotic factors including caspases. JC-1 is a $\Delta \Psi \mathrm{m}$ specific probe which indicates loss of $\Delta \Psi \mathrm{m}$ by changing fluorescence emission from red to green. As shown in Fig. 4, after $8 \mathrm{~h}$ OTA exposure, a time point when no cellular morphology changes could be observed, most control cells fluoresced red, while OTA treated cells turned green in an OTA concentration dependent manner in SH-SY5Y cells and primary neurons.

\section{Discussion}

Although the neurotoxic potential of OTA has been recognized [22, 29], the molecular mechanisms underlying its neurotoxicity have not yet been fully elucidated. Therefore the present study aimed to further characterize the impact of OTA on biomarkers of apoptosis and mitochondria membrane potential in neuronal cells in culture.

We have used primary neurons as a model since they represent an established model in neuroscience in order to study the regulation of apoptotic processes in neurons 


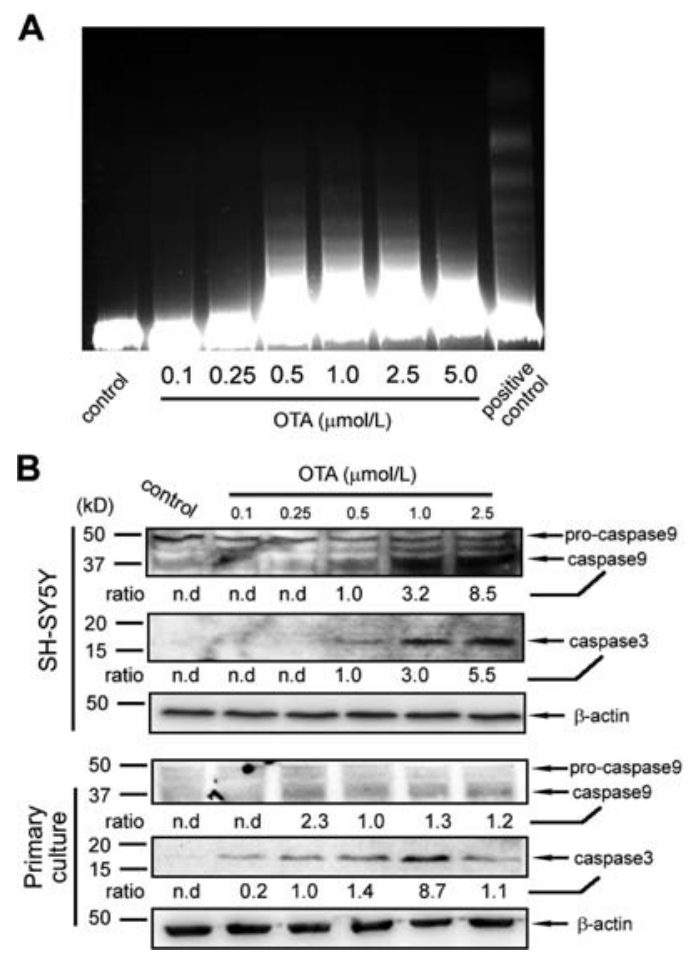

Fig. 3 OTA induced apoptosis in SH-SY5Y cells and primary neurons by caspase activation. A OTA induced DNA fragmentation in SH-SY5Y cells. Cells were exposed to increasing OTA concentrations for $48 \mathrm{~h}$, lyophilized apoptotic U937 cells were taken as positive control. B OTA induced caspase- 9 and caspase-3 activation both in SH-SY5Y cells and primary neurons after $24 \mathrm{~h}$ incubation. Caspase- 9 and caspase- 3 were determined by Western Blot analysis. Densitometric ratio of caspase- 9 and caspase- 3 to $\beta$-actin was

under defined experimental conditions. However, it needs to be taken into account that the neurons used in our study as well as in many other studies reported in the literature were isolated from rat brain $[22,35]$. In order to extrapolate our data also to humans we have decided to work in addition with SH-SY5 cells which are of human origin.

In the present study OTA exhibited neurotoxicity in SH-SY5Y cells and primary neurons at relatively low concentrations of 0.25 and $0.5 \mu \mathrm{mol} / \mathrm{L}$, respectively. This concentration is comparable to our previous cytotoxicity experiments in hepatocytes [13] indicating that neurons may be equally susceptible towards OTA induced cell death like hepatocytes. However, in comparison to our experiments in kidney tubulus cells $[5,6]$ neurons may be more susceptible to OTA than kidney cells.

Although OTA concentrations used in the present study under serum-free conditions were relatively low, it needs to be taken into account that these OTA concentrations are still higher than those concentrations detected in human and animal plasma. For example, OTA blood levels in
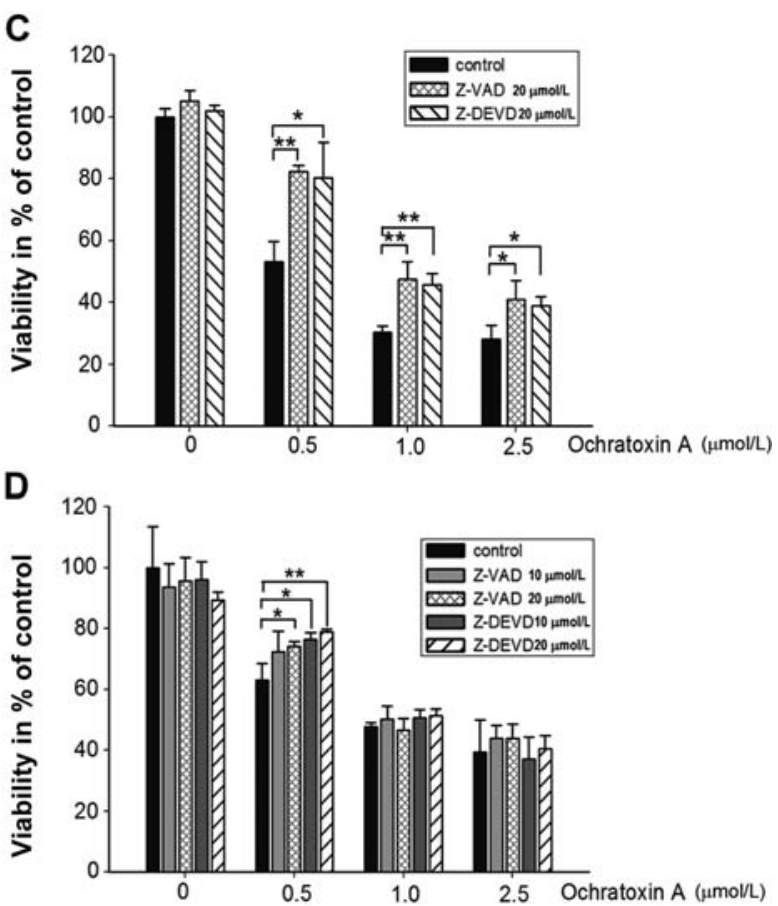

calculated; $n d=$ non-detectable). C, D Caspase inhibitors Z-VADfmk and Z-DEVD-fmk partly attenuated OTA induced cell death. Z-VAD-fmk and Z-DEVD-fmk were pre-cultured with SH-SY5Y and primary neurons for $24 \mathrm{~h}$, followed by another $24 \mathrm{~h}$ incubation with OTA. Cell viability was then determined by the neutral red assay. $* P<0.05 ; * * P<0.01$ versus control (without Z-VAD-fmk or Z-DEVD-fmk, $n=4-5$ )

healthy humans from European countries chronically exposed to OTA range between 0.45 and $2.95 \mathrm{nmol} / 1$ [20].

Previous studies have demonstrated that OTA crosses the blood brain barrier $[3,28]$ and exhibits neurotoxicity in laboratory rodents [27]. Our data suggest that OTA induced neurotoxicity is, at least partly mediated, by apoptosis. We have shown that both, caspase-9 and caspase-3, were activated in response to OTA treatment.

Furthermore, caspase inhibitors were effective in partly counteracting OTA induced neurocytotoxicity at low OTA concentrations but they were ineffective in restoring cell viability at the highest OTA concentrations (1 and $2.5 \mu \mathrm{mol} / \mathrm{L}$ ) used in our SH-SY5Y cell culture model. Thus neurotoxicity triggered by OTA is probably not only mediated by caspase- 3 activation.

In accordance to our OTA data, fumonisin $\mathrm{B}_{1}\left(\mathrm{FB}_{1}\right)$ [31] as well as trichothecene mycotoxins [15] have been demonstrated to induce apoptosis in cultured neurons.

Since in our study OTA induced apoptosis was accompanied by a loss of mitochondria membrane potential and Fas receptor regulated caspase-8 remained unchanged, it is 

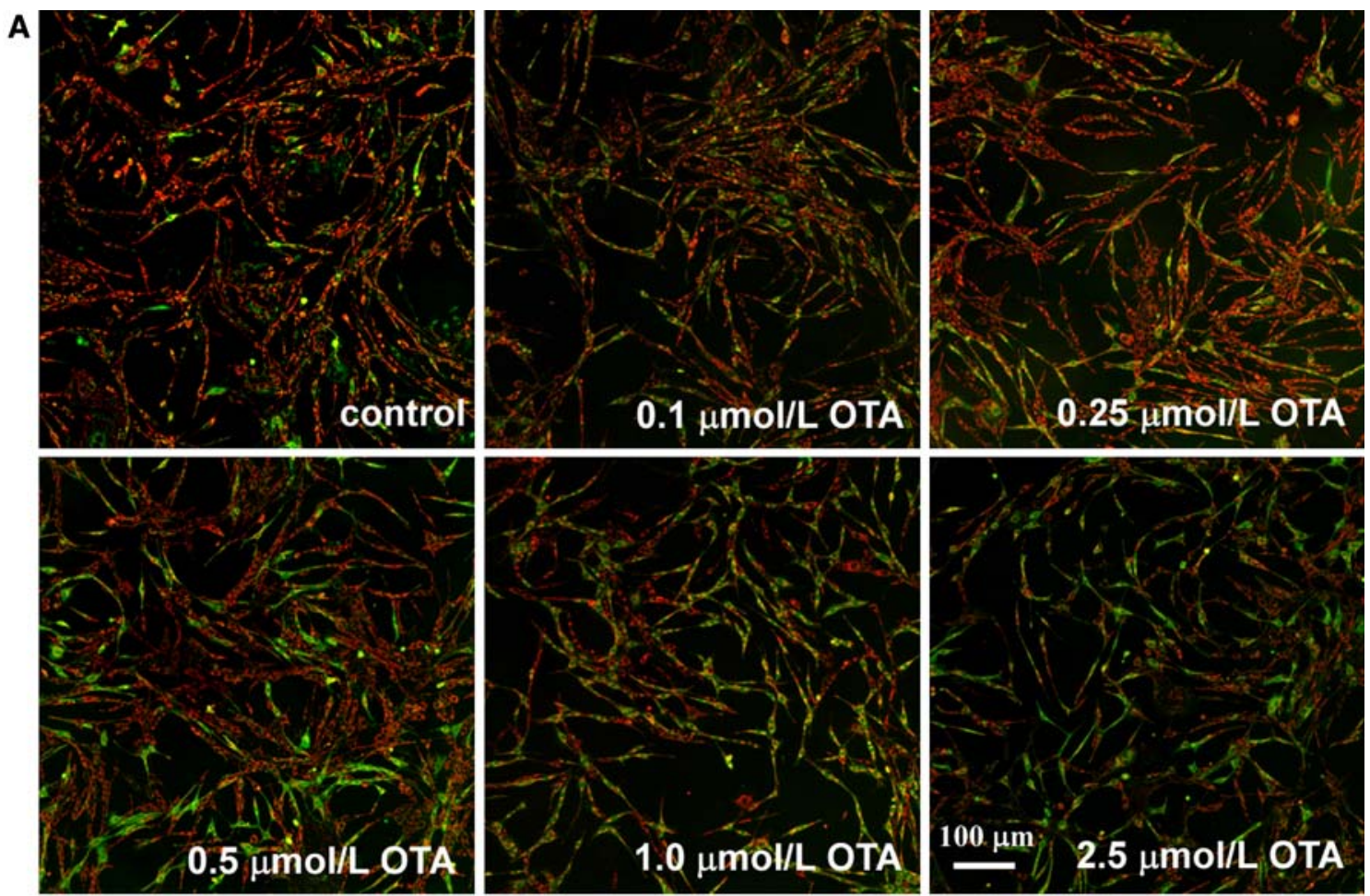

B
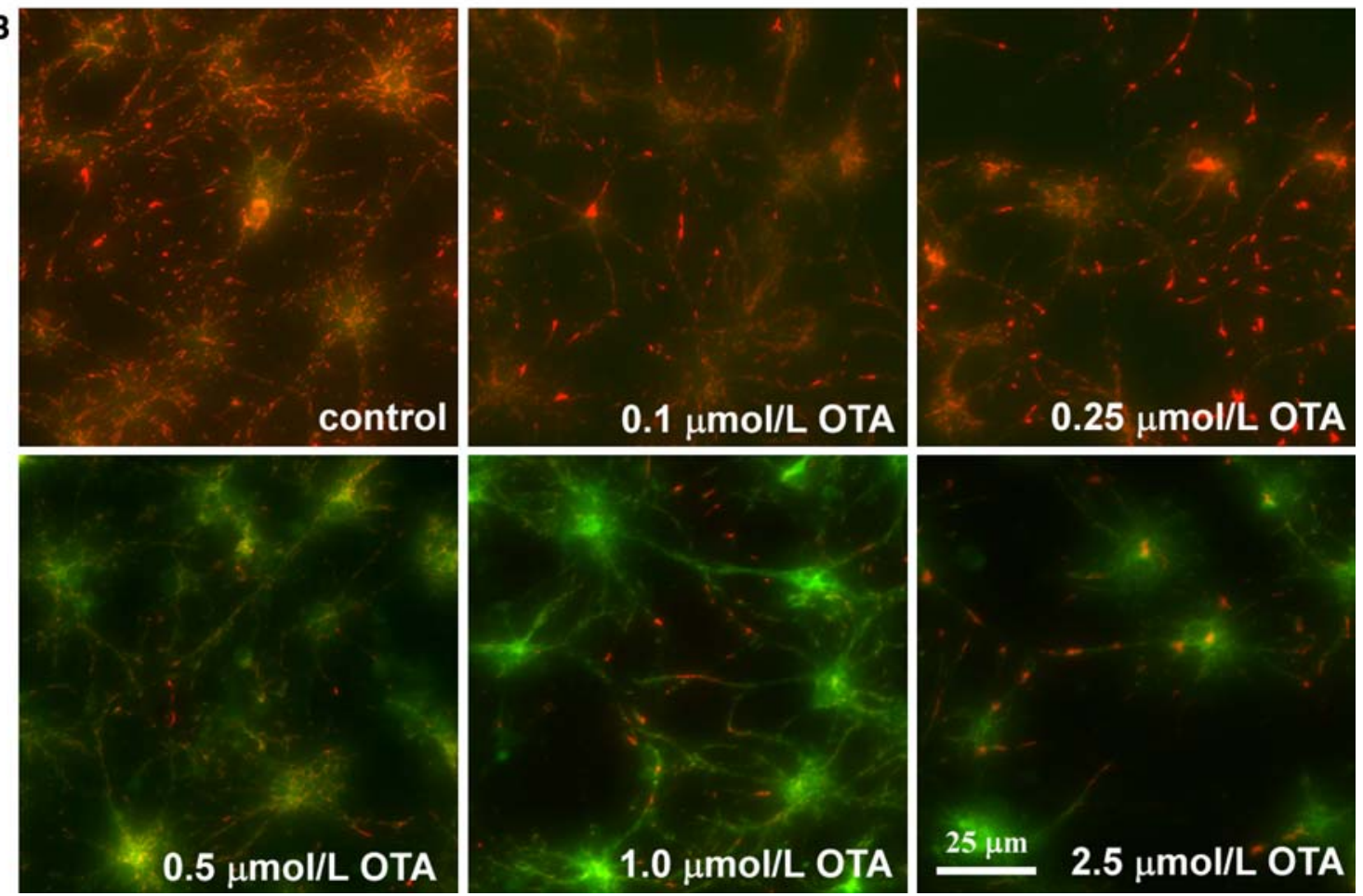

Fig. 4 Mitochondria membrane potential $\Delta \Psi \mathrm{m}$ assessment of SH-SY5Y cells (A) and primary neurons $(\mathbf{B})$ after $8 \mathrm{~h}$ OTA treatment by JC-1 staining. Changes in mitochondria membrane potential $\Delta \Psi \mathrm{m}$

likely that OTA induced cell death is mitochondria dependent. These findings are in line with current results [8] which emphasize a central role of the mitochondria in OTA induced caspase dependent apoptosis in liver cells. are indicated by changes in the red to green fluroscence ratio (In SHSY5Y cells, bar $=100 \mu \mathrm{m}$; in primary neurons, bar $=25 \mu \mathrm{m}$ )

Studies are warranted to investigate the effect of OTA on cytochrome c release and members of the Bcl-2 family in neurons. Furthermore studies regarding the effect of OTA on the action of protein kinases such as the 
phoshoinositide-3-kinase/Akt and mitogen-activated protein kinase, which are critical in regulating apoptotic signal transduction cascades are warranted [33].

Finally the triggering signal of OTA induced apoptosis in neuronal cells needs to be characterized. In vitro and in vivo data suggest an involvement of oxidative stress in OTA-mediated cytotoxicity $[1,4,16,17,23,30]$. In fact, we observed in kidney tubulus cells a significant increase in reactive oxygen species production after OTA treatment already at relatively low OTA concentrations (0.5$2.5 \mu \mathrm{mol} / \mathrm{L}$ ) [5] which were similar to those concentrations we used in the present study in neurons. Our group has recently shown that the activities of the redox-regulated transcription factors Nrf2 and AP-1 are impaired by OTA $[5,6]$. Nrf2 is a basic leucine zipper transcriptional activator essential for the coordinated transcriptional induction of antioxidant and xenobiotic metabolizing enzymes [21]. Importantly, OTA significantly decreased gamma-glutamylcysteinyl synthetase levels in kidney tubulus cells via a Nrf2 dependent mechanism [6]. Gamma-glutamylcysteinyl synthetase is the rate limiting enzyme of glutathione synthesis and depletion of cellular glutathione often leads to apoptosis [11].

Overall current data indicate that OTA induces programmed cell death both in SH-SY5Y cells and in primary neurons. Taken into account that many neurodegenerative diseases including Alzheimer's and Parkinson's disease are related to neuronal cell death and that the central nervous system tissue has limited regenerative capacity [12], it is of importance to limit the potential damage caused by ochratoxin A and other mycotoxins, due to a reduction of their occurrence in the food chain.

\section{References}

1. Baudrimont I, Ahouandjivo R, Creppy EE (1997) Prevention of lipid peroxidation induced by ochratoxin $\mathrm{A}$ in Vero cells in culture by several agents. Chem Biol Interact 104:29-40

2. Belmadani A, Tramu G, Betbeder AM et al (1998) Subchronic effects of ochratoxin A on young adult rat brain and partial prevention by aspartame, a sweetener. Hum Exp Toxicol 17:380-386

3. Belmadani A, Tramu G, Betbeder AM et al (1998) Regional selectivity to ochratoxin $\mathrm{A}$, distribution and cytotoxicity in rat brain. Arch Toxicol 72:656-662

4. Bertelli AA, Migliori M, Filippi C et al (2005) Effect of ethanol and red wine on ochratoxin a-induced experimental acute nephrotoxicity. J Agric Food Chem 53:6924-6929

5. Boesch-Saadatmandi C, Loboda A, Jozkowicz A et al (2008) Effect of ochratoxin A on redox-regulated transcription factors, antioxidant enzymes and glutathione-S-transferase in cultured kidney tubulus cells. Food Chem Toxicol 46:2665-2671

6. Boesch-Saadatmandi C, Wagner AE, Graeser AC et al (2008b) Ochratoxin A impairs Nrf2-dependent gene expression in porcine kidney tubulus cells. J Anim Physiol Anim Nutr (Berl). doi: 10.1111/j.1439-0396.2008.00838.x
7. Borenfreund E, Puerner JA (1985) Toxicity determined in vitro by morphological alterations and neutral red absorption. Toxicol Lett 24:119-124

8. Bouaziz C, El Dein OS, El Golli E et al (2008) Different apoptotic pathways induced by zearalenone, T-2 toxin and ochratoxin A in human hepatoma cells. Toxicology 254:19-28

9. Brewer GJ, Torricelli JR, Evege EK et al (1993) Optimized survival of hippocampal neurons in B27-supplemented Neurobasal, a new serum-free medium combination. J Neurosci Res 35:567-576

10. Castegnaro M, Canadas D, Vrabcheva T et al (2006) Balkan endemic nephropathy: role of ochratoxins A through biomarkers. Mol Nutr Food Res 50:519-529

11. Franco R, Dehaven WI, Sifre MI et al (2008) Glutathione depletion and disruption of intracellular ionic homeostasis regulate lymphoid cell apoptosis. J Biol Chem. doi: 10.1074/jbc. M807061200

12. Friedlander RM (2003) Apoptosis and caspases in neurodegenerative diseases. N Engl J Med 348:1365-1375

13. Hundhausen C, Bosch-Saadatmandi C, Augustin K et al (2005) Effect of vitamin $\mathrm{E}$ and polyphenols on ochratoxin A-induced cytotoxicity in liver (HepG2) cells. J Plant Physiol 162:818-822

14. IARC (1993) Ochratoxin A. In: IARC monographs on the evaluation of the carcinogenic risks to humans: some naturally occurring substances. food items and constituents, heterocyclic aromatic amines and mycotoxins, vol 56. International Agency for Research on Cancer, Geneva, pp 26-32

15. Islam Z, Amuzie CJ, Harkema JR et al (2007) Neurotoxicity and inflammation in the nasal airways of mice exposed to the macrocyclic trichothecene mycotoxin roridin a: kinetics and potentiation by bacterial lipopolysaccharide coexposure. Toxicol Sci 98:526-541

16. Kamp HG, Eisenbrand G, Janzowski C et al (2005) Ochratoxin A induces oxidative DNA damage in liver and kidney after oral dosing to rats. Mol Nutr Food Res 49:1160-1167

17. Kamp HG, Eisenbrand G, Schlatter J et al (2005) Ochratoxin A: induction of (oxidative) DNA damage, cytotoxicity and apoptosis in mammalian cell lines and primary cells. Toxicology 206:413425

18. Kuiper-Goodman T (1996) Risk assessment of ochratoxin A: an update. Food Addit Contam 13(Suppl):53-57

19. Luhe A, Hildebrand H, Bach U et al (2003) A new approach to studying ochratoxin A (OTA)-induced nephrotoxicity: expression profiling in vivo and in vitro employing cDNA microarrays. Toxicol Sci 73:315-328

20. Mally A, Hard GC, Dekant W (2007) Ochratoxin A as a potential etiologic factor in endemic nephropathy: lessons from toxicity studies in rats. Food Chem Toxicol 45:2254-2260

21. McMahon M, Itoh K, Yamamoto M et al (2001) The Cap'n'Collar basic leucine zipper transcription factor Nrf2 (NFE2 p45-related factor 2) controls both constitutive and inducible expression of intestinal detoxification and glutathione biosynthetic enzymes. Cancer Res 61:3299-3307

22. Monnet-Tschudi F, Sorg O, Honegger P et al (1997) Effects of the naturally occurring food mycotoxin ochratoxin A on brain cells in culture. Neurotoxicology 18:831-839

23. Petrik J, Zanic-Grubisic T, Barisic K et al (2003) Apoptosis and oxidative stress induced by ochratoxin $\mathrm{A}$ in rat kidney. Arch Toxicol 77:685-693

24. Petzinger E, Ziegler K (2000) Ochratoxin A from a toxicological perspective. J Vet Pharmacol Ther 23:91-98

25. Pfohl-Leszkowicz A, Manderville RA (2007) Ochratoxin A: an overview on toxicity and carcinogenicity in animals and humans. Mol Nutr Food Res 51:61-99

26. Ringot D, Chango A, Schneider YJ et al (2006) Toxicokinetics and toxicodynamics of ochratoxin $\mathrm{A}$, an update. Chem Biol Interact 159:18-46 
27. Sava V, Reunova O, Velasquez A et al (2006) Acute neurotoxic effects of the fungal metabolite ochratoxin-A. Neurotoxicology 27:82-92

28. Sava V, Reunova O, Velasquez A et al (2006) Can low level exposure to ochratoxin-A cause parkinsonism? J Neurol Sci 249:68-75

29. Sava V, Velasquez A, Song S et al (2007) Adult hippocampal neural stem/progenitor cells in vitro are vulnerable to the mycotoxin ochratoxin-A. Toxicol Sci 98:187-197

30. Schaaf GJ, Nijmeijer SM, Maas RF et al (2002) The role of oxidative stress in the ochratoxin A-mediated toxicity in proximal tubular cells. Biochim Biophys Acta 1588:149-158

31. Stockmann-Juvala H, Naarala J, Loikkanen J et al (2006) Fumonisin B1-induced apoptosis in neuroblastoma, glioblastoma and hypothalamic cell lines. Toxicology 225:234-241
32. Wang Z, Zhang X, Wang $\mathrm{H}$ et al (2007) Neuroprotective effects of icaritin against beta amyloid-induced neurotoxicity in primary cultured rat neuronal cells via estrogen-dependent pathway. Neuroscience 145:911-922

33. Yuan J, Yankner BA (2000) Apoptosis in the nervous system. Nature 407:802-809

34. Zuliani T, Duval R, Jayat C et al (2003) Sensitive and reliable JC-1 and TOTO-3 double staining to assess mitochondrial transmembrane potential and plasma membrane integrity: interest for cell death investigations. Cytometry A 54:100-108

35. Zurich MG, Lengacher S, Braissant $O$ et al (2005) Unusual astrocyte reactivity caused by the food mycotoxin ochratoxin A in aggregating rat brain cell cultures. Neuroscience 134:771-782 